\title{
Defensive high-anxious individuals with chronic back pain demonstrate different treatment choices and patient persistence.
}

\author{
Z.C. Franklin, MSc; N.C. Smith, PhD; and N. E. Fowler*, PhD
}

Manchester Metropolitan University, Institute for Performance Research, Department of Exercise and Sport Science Manchester Metropolitan University, Crewe Campus, Crewe Green Road, Crewe, Cheshire, CW1 5DU. United Kingdom (email:

z.franklin@mmu.ac.uk; n.c.smith@mmu.ac.uk;

n.fowler@mmu.ac.uk)

*Corresponding author and requests for reprints should be addressed to Professor Neil Fowler, Institute for Performance Research, Department of Exercise and Sport Science, Manchester Metropolitan University, Crewe Campus, Crewe Green Road, Crewe, Cheshire, CW1 5DU. United Kingdom (email: n.fowler@mmu.ac.uk; Tel 0161247 5466). 


\begin{abstract}
The aim of this study is to determine whether the experience of, and response to chronic back pain was different for defensive high-anxious individuals than other personality types (defensive high-anxious, high-anxious, repressor and low-anxious). Participants $(\mathrm{n}=111)$ were recruited from a heterogeneous sample of individuals who had reported back pain within the last 6 months. Self-report measures of trait anxiety and defensiveness were used to determine personality type. In addition, pain, treatment history, disability, depression and satisfaction with treatment were recorded. Despite reporting similar levels of pain to other personality groups, defensive high-anxious individuals reported significantly greater disability and depression $(\mathrm{p}<0.01)$. Of the defensive high-anxious individuals, $92 \%$ sought more than one intervention. In comparison, repressors predominantly self-managed their pain with only $10 \%$ utilising more than one intervention. Surprisingly, there were no differences in treatment satisfaction between the four groups. The present study suggests that personality type is an important factor influencing patients' treatment options, with defensive high anxious individuals substantially more likely to seek multiple interventions and remain within the care system. The present study provides a basis for future research into the role of personality type in the management of chronic pain.
\end{abstract}

Key words: Personality type, Defensive high-anxious, Repressors, Back pain, Treatment options. 


\section{First copyedit complete.}

\section{Introduction}

Back pain is one of the most prevalent injuries in the general population with, in Britain, an annual prevalence rate of $30-40 \%$ and a lifetime prevalence of $70-80 \%$ (Walsh, Cruddas, \& Coggon, 1992). Typically, symptoms of acute low back pain improve within approximately six weeks for $70-90 \%$ of cases: whereas, in chronic back pain, $4-7 \%$ are not able to return to work within six months and account for approximately $75 \%$ of the medical and social costs of the condition (Maetzel \& Li, 2002). Back pain has obvious effects on the individual, but there is also a significant impact on the economy through medical care costs and lost productivity (NICE, 2009a).

Over recent years, there has been considerable interest in the role of psychosocial factors in the response to and management of chronic back pain (Linton, 2000; Woby, Roach, Urmston, \& Watson, 2007). It has been well established that anxiety has an impact upon pain perception and treatment outcome (Bair, et al., 2013; Bair, Damush, Sutherland, \& Kroenke, 2008; Kroenke, et al., 2013). Anxiety and defensiveness (social desirability) have been shown to influence the way patients respond to treatment and health outcomes within a chronic illness population (Myers, 2010; Phipps \& Steele, 2002; Prasertsri, Holden, Keefe, \& Wilkie, 2011), however, little is known about the combination of anxiety and defensiveness in a population with chronic musculoskeletal pain.

Weinberger, Schwartz and Davidson (1979) identified four personality groupings that show different emotional reactions and behaviours when confronted with stressful situations: high-anxious (HA); defensive high-anxious (DHA); low-anxious (LA); and repressor (REP) types. The taxonomy of the four profiles is based on individuals' self-report of trait anxiety 
and defensiveness. DHA individuals report high trait anxiety and high defensiveness; highanxious individuals report high trait anxiety and low defensiveness; repressors report low trait anxiety and high defensiveness; and low-anxious individuals report both low trait anxiety and defensiveness. Based on Weinberger et al.’s (1979) classifications, Eysenck (1997) proposed the four-factor theory of trait anxiety, which suggested that the emotional experience of anxiety depends on the processing of four sources of information. There are two main assumptions within the theory that serve to influence the processing of the four sources of information. First, individual differences in trait anxiety and defensiveness affect the operation of attentional and interpretive biases that serve to either magnify or minimise the processing of emotion relevant stimuli. Secondly, these cognitive biases are affected by the prevailing level of state anxiety. Specifically, the effect of these biases becomes greater as state anxiety increases. According to the four-factor theory, the emotional experience of anxiety is the consequence of the processing of the following four sources of information; (i) the individual's immediate cognitive appraisal of the environment as threating; (ii) the negative cognitions that arise about possible, future events (e.g. worries); (iii) the individual's interpretation of their own behaviour; (iv) the attention to and interpretation of the individual's physiological activity.

The four-factor theory makes the following prediction linked to Weinberger et al.'s (1979) four personality groups. High-anxious individuals are predicted to exhibit both attentional and interpretive biases that amplify potential threat and lead them to interpret ambiguous stimuli as threatening. In contrast, repressors have opposite attentional and interpretive biases, which lead them to direct attention away from threatening information and interpret ambiguous stimuli as non-threatening. In low-anxious individuals, no such biases are assumed to operate. The cognitive biases of defensive high-anxious individuals 
have not been adequately described in the literature although are often assumed to be similar to those of high-anxious individuals. However, the relatively high prevalence of defensive high anxious individuals in pain management programmes (Lewis, Fowler, Woby and Holmes, 2012) suggests that there may be an important interaction of defensiveness and anxiety and a different pattern of cognitive biases for this group.

Repressor and defensive high-anxious individuals are rare in the general population (Myers, 2010), however, Creswell and Chalder (2001) found that $46 \%$ of Chronic Fatigue Syndrome patients were classified as defensive high-anxious, compared with only $17 \%$ of the control population. Lewis, Fowler, et al. (2012) also identified a high proportion of defensive high-anxious individuals within a group of patients referred to an active rehabilitation programme for chronic back pain. Based on Eysenck's (1997) theory, it could be that defensive high-anxious individuals are more likely to interpret their pain in a negative manner as a result of their cognitive biases which predispose them to attend to and interpret stimuli as threatening and thus present for treatment more frequently than repressors. With chronic back pain or Chronic Fatigue Syndrome, repressors may be able to avoid their pain and self-manage treatment, an option not available for conditions with a more clearly defined diagnosis and treatment pathway.

Derakshan, Eysenck and Myers (2007) proposed a vigilance-avoidance theory (VAT) of threat processing specifically characteristic of repressor individuals. The VAT suggests that when repressors experience a self-relevant threat, there are two stages of processing; the first is a rapid, vigilance stage that involves automatic and non-conscious processes, reported to take up to $500 \mathrm{~ms}$ (Calvo \& Eysenck, 2000). The second stage is avoidance, this is a more consciously controlled and strategic process aimed at threat avoidance. Repressors' use of an 
avoidant attentional bias depends on their cognitive appraisal of the situation. They will primarily engage in vigilance followed by avoidance when exposed to self-relevant threats, such as threats to their psychological or physical well-being (Derakshan, et al., 2007). In addition, research has found repressors protect their self-esteem by biased recall of fewer negative self-relevant memories (Ashley \& Holtgraves, 2003).

These attentional and memory biases appear likely to influence the interpretation of pain and disability. Heightened vigilance to potentially threatening symptoms is expected to capture the attention of high-anxious and defensive high-anxious individuals. In addition, as a consequence of interpretive biases, they are more likely to interpret ambiguous sensory events as threatening. In relation to these predictions, we would expect defensive highanxious participants to continue to highlight their pain and interpret it as both serious and threatening. Previous research has found a strong association between anxiety and various markers of pain and treatment success (Viggers \& Caltabiano, 2012). In this study, we propose that the combination of trait anxiety and defensiveness could influence the way individuals interpret and respond to their chronic pain.

The overall aim of this study is to further the understanding of how anxiety and defensiveness interact to influence the experience of, and response to, back pain. More specifically, the study aims to determine whether treatment options and satisfaction in individuals with chronic back pain differ across the four personality groups. We hypothesise that: 1) defensive high-anxious individuals would report greater levels of pain and disability compared to the other three personality types; 2) defensive high-anxious individuals would seek more treatment options and be less satisfied with their treatment compared to the other 
three personality types and; 3) the majority of repressors would self-manage their back pain compared to using any other treatment option.

\section{Method}

\subsection{Procedure}

To investigate the hypothesised link between personality traits and the experience of chronic back pain, a cross-sectional study design was employed. Participants were told that the purpose of the study was to determine whether differences exist in the way individuals interpret and respond to stresses among individuals with a history of back pain. The study received approval from the Departmental Ethics Committee at Manchester Metropolitan University. Participants completed a booklet of questionnaires taking approximately 15-20 minutes. Participants received the questionnaire by email or post, completed it within their own time and returned it to the experimenter.

\subsection{Participants}

Participants were recruited from a heterogeneous population of target shooters and hockey players who were chosen because of the high prevalence of back pain in these groups. Approximately 500 questionnaires were distributed, of which 111 (22\%) participants who had reported suffering back pain in the past six months responded . Fifty-seven participants (mean age $=46.6 ; \mathrm{SD} \pm 15.1$ ) years) were used in the final analysis based on tertiary splits (set at $33 \%$ and $66 \%$ ) on the trait component of the State and Trait Anxiety Inventory (STAI) (Spielberger, Gorssuch, Lushene, Vagg, \& Jacobs, 1983) and the Marlowe-Crowne Social Desirability Scale (MC-SDS) (Strahan \& Gerbasi, 1972)(Table 1). Percentile splits set at 33\% and $66 \%$ were chosen over median splits to ensure the extremes were taken on each scale and 
the four groups differed in both trait anxiety and defensiveness. Repressors $(n=10)$ reported higher than 8 on the MC-SDS and lower than 29 on the STAI; low-anxious $(n=15)$ individuals reported lower than 5 on MC-SDS and lower than 29 on the STAI; defensive high-anxious $(n=14)$ individuals reported higher than 8 on MC-SDS and higher than 40 on the STAI; high-anxious $(n=18)$ individuals reported lower than 5 on the MC-SDS and higher than 40 on the STAI.

\subsection{Measures}

\subsubsection{Personality type}

To assess defensiveness and to discriminate repressor individuals from low-anxious individuals and defensive high-anxious from high-anxious individuals the 10-item short form of the MC-SDS (Strahan \& Gerbasi, 1972) was used. The scale consists of items which are culturally approved but unlikely to occur. For example, "I am always willing to admit it when I make a mistake". The participants answered either true or false to each statement. Reynolds (1982) reported an internal consistency alpha coefficient of 0.66 . In addition, a correlation coefficient of $r=0.9(p<0.001)$ was reported between the 10 item MC-SDS and the original 33 item MC-SDS (Crowne \& Marlowe, 1960), providing support for the shorter version.

The STAI (Spielberger, et al., 1983) was used to assess trait anxiety. It consists of 20 statements (e.g. "I lack self-confidence") that participants rate on a scale of 1 (not at all) to 4 (very much so), with a score range of between 20 to 80 . The trait component of the STAI has a test-retest reliability of between .73 and .86 reported by Spielberger et al. (1983).

\subsubsection{Depression}


The Hospital Anxiety and Depression Scale (Zigmond \& Snaith, 1983) was used to assess participants' depression. This is a 14-item questionnaire for use with patients with somatic complaints; assessing anxiety (7-items) (e.g. "I feel tense or 'wound-up"”) and depression (7items) (e.g. "I feel as if I am slowed down”). All items are scored on a 4-point Likert scale from 0 to 3 . Higher scores demonstrate greater levels of anxiety and depression. The anxiety and depression scales both have validity and reliability. Upadhyaya and Stanley (1993) found a correlation coefficient for the anxiety and depression subscales of between 0.69 and 0.75 respectively $(\mathrm{p}<0.001)$. Bjelland, Dahl, Haug and Neckelmann (2002) reported a validity Cronbach alpha for the anxiety and depression scales of 0.83 and 0.82 respectively.

\subsubsection{Disability}

The Roland Morris Disability questionnaire (RDQ) (Roland \& Morris, 1983) was used to assess disability due to back pain. This is a standard 24 item self-report measure where participants answer either true or false to each statement about how they are feeling today (e.g. "I stay at home most of the time because of my back pain"). Scores range from 0 to 24 , with higher scores reflecting greater disability. This measure has an acceptable level of reliability with a correlation coefficient of 0.91 (Roland \& Morris, 1983) and an acceptable level of validity Cronbach alpha of 0.90 (Roland \& Fairbank, 2000).

\subsubsection{Treatment history, satisfaction and current pain intensity}

Satisfaction with treatment and current pain intensity was measured on a 10 point numerical rating scale. Participants were asked to rate their pain over the past 24 hours on a scale from (0) "no pain" to (10) "worst possible pain". Participants were also asked to rate their satisfaction with treatment outcome and with treatment care on a scale ranging from $(0)$ 
"not satisfied at all" to (10) "very satisfied". Participants were asked to record their treatment history for their back pain (e.g. self-manage, doctor, physiotherapist)

\subsubsection{Data Analysis}

Percentile points (set at $33 \%$ and $66 \%$ ) on the MC-SDS (defensiveness) and STAI (trait anxiety sub-scale) were used to define the four personality groups a statistical heterogeneity check was performed on the four personality groups, prior to the main data analysis, to ensure they differed in trait anxiety and defensiveness. A Multivariate Analysis of Variance analysis (MANOVA) and Analysis of Variance analysis (ANOVA) was used to assess between-group differences in self-reported depression, disability, pain (worst pain and current pain) and treatment satisfaction. A chi-square was run to assess if there were differences in the distribution of treatment choices between personality groups.

\section{Results}

\subsection{Trait anxiety and defensiveness: heterogeneity check}

The one-way ANOVA for the trait anxiety sub-scale revealed an overall significant effect, $F(3,56)=22.348,(\mathrm{p}<0.01)$. Post-hoc Tukey HSD analysis confirmed significant differences between the trait anxiety scores of the high-anxious and low-anxious groups $(\mathrm{p}<$ 0.05: $E S=0.6)$ and the defensive high-anxious and repressor groups $(\mathrm{p}<0.05: E S=0.8)$. The defensiveness scores showed significant differences between the four groups, $F(3,56)=$ 34.094, $\mathrm{p}<0.01$. Post-hoc Tukey analysis confirmed significant differences in defensiveness between the defensive high-anxious and low-anxious groups $(\mathrm{p}<0.05: E S=0.7)$ and the repressor and high-anxious groups $(\mathrm{p}<0.05: E S=0.8)$. 


\subsection{Treatment Options}

The chi-square demonstrated a significant association between personality type and the type of intervention utilised $\chi^{2}(6)=13.84, p<0.05$. Defensive high-anxious participants reported making use of the greatest number of treatment options, with $92 \%$ seeking more than one intervention. Sixty percent of repressors self-managed their back pain and only $10 \%$ sought more than one source of treatment. Repressors were the least likely to make use of the physiotherapist, doctor or any other treatment option (Figure 1). The most common 'other' treatment options used were chiropractor, sports massage and osteopath.

\subsection{Depression, treatment satisfaction, pain, and disability}

The MANOVA showed a significant group main effect for outcome measures (Wilks' Lambda $=0.520, \mathrm{~F}(3,56)=2.417, p<0.01)$. A follow-up between-group ANOVA and a Post-hoc Tukey HSD analysis showed that defensive high-anxious individuals reported significantly $(F(3,56)=9.025, \mathrm{p}<0.05)$ higher depression than repressor $(E S=0.7)$, highanxious $(E S=0.4)$ and low-anxious $(E S=0.6)$ groups. No significant differences were found between the low-anxious and repressor, or the repressor and high-anxious groups.

Despite the defensive high-anxious individuals seeking more interventions, there were no significant differences between the four groups for treatment satisfaction $(p>0.05)$ and no significant differences between the four groups for worst or present pain.

Follow-up between group ANOVA for disability did show a significant difference between the four groups $(F(3,56)=5.165, \mathrm{p}<0.05)$. A Post-hoc Tukey HSD analysis revealed that defensive high-anxious and high-anxious individuals reported significantly $(\mathrm{p}<$ 
$0.05)$ higher disability than repressors. No significant differences were found between the low-anxious and the other three groups.

\section{Discussion:}

The aim of the study was to determine whether treatment options and satisfaction in individuals with chronic back pain differ across the four personality groups. All four personality groups exhibited similar levels of pain and satisfaction with treatment, but differed significantly in how they interpreted this pain and the resulting patterns of disability, depression and treatment.

The defensive high-anxious group reported the same pain as the other three groups, but perceived this pain to be more debilitating and consequentially reported greater painrelated depression. Although levels of both pain and disability are relatively low in this study compared to clinically based studies (Lewis, Holmes, Woby, Hindle, \& Fowler, 2012; Woby, Watson, Roach, \& Urmston, 2005) where RDQ scores typically fall in the range 13-17 and pain in the range 8.5-9.1(Koleck, Mazaux, Rascle, \& Bruchon-Schweitzer, 2006; Lewis, Holmes et al., 2012; Meeus, Nijs, Van Mol, Truijen, \& De Meirleir, 2012; Woby, Watson, Roach, \& Urmston, 2004), these values are similar to the $(\mathrm{RDQ}=6.1$ and Pain $=3.1$ scores $)$ values for participants in the study by Healey, Fowler, Burden and McEwan (2005). Although the sample fall at the lower end of the pain and disability spectrum, when contrasted to clinically based groups, the population can be considered to be more representative of the wider population of back pain sufferers. This sample also captures participants often excluded from other analyses, but who impact upon the social and economic cost of the condition. 
Despite reporting similar levels of pain and satisfaction with treatment, the DHA group were the most likely to seek multiple forms of intervention. Over $90 \%$ sought intervention from at least two sources, more than double that of the other groups. The tendency for defensive high-anxious individuals to seek continued intervention in the care setting may help to explain the high proportion of participants with this personality type found within clinically based studies of chronic low back pain (Lewis, Fowler et al., 2012) and Chronic Fatigue Syndrome (Creswell \& Chalder, 2001). In these conditions, referral for treatment is often based on the perceived persistence and severity of the condition as reported by the patient (NICE, 2009b). Referral to a hospital-based physiotherapy and psychologybased programme of the type investigated by Lewis, Fowler et al., (2012) would normally only follow failure of one or more primary care interventions e.g. manual therapy, physiotherapy, exercise, acupuncture etc. The evidence of the current study demonstrates that amongst a group of back pain sufferers with similar levels of self-reported pain, those with a defensive high-anxious profile were more likely to present for and utilise multiple forms of intervention. Early identification of personality group may provide a means to more appropriate target interventions and reduce the total care and other costs associated with multiple interventions.

We have identified that defensive high-anxious individuals are more likely to highlight their pain, report it as more debilitating and report higher depression. Consequently, it could be argued that the combination of high trait anxiety and high defensiveness should be taken into account when formulating a treatment programme if these individuals are more likely to report both higher depression and disability. Studies have already found that reductions in depression are strongly related to reductions in disability and pain (Woby, 
Roach, Urmston, \& Watson, 2008), however, longitudinal studies are required to identify the relationship between personality groups, cognitive factors such as depression and levels of disability. Although there were low disability levels found within this study when compared to clinically based studies, we would expect to find similar results in relation to the personality traits in more severely affected groups.

In contrast to the defensive high-anxious group, repressors had the highest proportion of individuals who self-managed their back pain, with the lowest percentage of individuals who sought other treatment options. This is a critical finding, as previous research has primarily been conducted within a specific rehabilitation context and with a relatively low proportion of repressor individuals. Previous review articles have suggested that repressors respond better to treatment when they have a feeling of personal control (Myers, 2010). Within this study, the majority of repressors reported self-managing their pain and high satisfaction with this form of treatment. In addition, repressors reported significantly lower disability and depression than the defensive high-anxious group, this could be a result of their cognitive biases causing them to interpret pain as non-threatening and choose to self-manage rather than consult a health professional.

The following limitations of this study should be taken into account. Firstly, the crosssectional nature of this study means that causal inferences cannot be made. In order to confirm whether the combination of high defensiveness and high anxiety causes patients to be more persistent and influences treatment outcome, longitudinal studies are required. Secondly, the limited number of questions about satisfaction may cause patients to interpret the question differently. The question was related to overall treatment, which could have been interpreted as satisfaction with pain or satisfaction with individual treatment options. Future 
research should investigate satisfaction as a multidimensional concept, investigating both satisfaction with improvement in pain and the effectiveness of treatment (e.g. leaving the care system and limited or no pain). Thirdly, participants were recruited from a convenient sample of individuals who have back pain, rather than patients from a clinical population.

Consequently, the reported levels of disability are lower than would normally be found in a clinical population. Although the sample fall at the lower end of the pain and disability spectrum, when contrasted to clinically based groups, the population can be considered representative of the wider back pain population and may better reflect the consistency normally seen in primary care settings.

\subsection{Conclusions}

The present study provides evidence that dispositional anxiety and defensiveness are important factors influencing patients' symptomatology and treatment options. The combination of trait anxiety and defensiveness may provide a greater insight than considering anxiety alone. In particular, defensive high-anxious individuals appear more likely to demonstrate a persistent re-presentation for treatment and repressors may prefer to selfmanage their treatment. Future research should investigate the role of personality type in explaining variations in treatment satisfaction experienced by patients recruited from a clinical environment. In addition, trait personality type could also help explain the way psychological factors mediate and influence clinical outcome. Further, such research may also help explain and predict why individuals with similar initial symptoms may stay within or leave the care system. 


\section{References}

Ashley, A., \& Holtgraves, T. (2003). Repressors and memory: Effects of self-deception, impression management, and mood. Journal of Research in Personality, 37(4), 284296.

Bair, M. J., Poleshuck, E. L., Wu, J., Krebs, E. K., Damush, T. M., Tu, W., et al. (2013). Anxiety but not social stressors predict 12-month depression and pain severity. The Clinical journal of pain, 29(2), 95-101.

Bair, M. J. W., J., Damush, T. M., Sutherland, J. M., \& Kroenke, K. (2008). Association of depression and anxiety alone and in combination with chronic musculoskeletal pain in primary care patients. Psychosomatic Medicine, 70(8), 890-897.

Bjelland, I., Dahl, A. A., Haug, T. T., \& Neckelmann, D. (2002). The validity of the Hospital Anxiety and Depression Scale: an updated literature review. Journal of Psychosomatic Research, 52(2), 69-77.

Calvo, M. G., \& Eysenck, M. W. (2000). Early vigilance and late avoidance of threat processing: Repressive coping versus low/high anxiety. Cognition \& Emotion, 14(6), 763-787.

Creswell, C., \& Chalder, C. (2001). Defensive coping styles in chronic fatigue syndrome. Journal of Psychosomatic Research, 51, 607-610.

Crowne, D. P., \& Marlowe, D. (1960). A new scale of social desirability independent of psychopathology. Journal of Consulting Psychology, 24(4), 349.

Derakshan, N., Eysenck, M. W., \& Myers, L. B. (2007). Emotional information processing in repressors: The vigilance-avoidance theory. Cognition and Emotion, 21(8), 15851614.

Eysenck, M. W. (1997). A new theory of trait anxiety. Anxiety and Cognition: A Unified Theory. Hove: Psychology Press.

Healey, E., Fowler, N., Burden, A., \& McEwan, I. M. (2005). The influence of different unloading positions upon stature recovery and paraspinal muscle activity. Clinical biomechanics, 20(4), 365-371.

Koleck, M., Mazaux, J.-M., Rascle, N., \& Bruchon-Schweitzer, M. (2006). Psycho-social factors and coping strategies as predictors of chronic evolution and quality of life in patients with low back pain: a prospective study. European Journal of Pain, 10(1), 111.

Kroenke, K., Outcalt, S., Krebs, E., Bair, M. J., Wu, J., Chumbler, N., et al. (2013). Association between anxiety, health-related quality of life and functional impairment in primary care patients with chronic pain. General Hospital Psychiatry, 35, 359-365.

Lewis, S., Holmes, P., Woby, S., Hindle, J., \& Fowler, N. (2012). The relationships between measures of stature recovery, muscle activity and psychological factors in patients with chronic low back pain. 17, 1, 27-33.

Lewis, S. E., Fowler, N. E., Woby, S. R., \& Holmes, P. S. (2012). Defensive coping styles, anxiety and chronic low back pain. Physiotherapy, 98(1), 86-88.

Linton, S. J. (2000). A review of psychological risk factors in back and neck pain. Spine, 25(9), 1148-1156.

Maetzel, A., \& Li, L. (2002). The economic burden of low back pain: a review of studies published between 1996 and 2001. Best Practice \& Research Clinical Rheumatology, 16(1), 23-30.

Meeus, M., Nijs, J., Van Mol, E., Truijen, S., \& De Meirleir, K. (2012). Role of psychological aspects in both chronic pain and in daily functioning in chronic fatigue syndrome: a prospective longitudinal study. Clinical Rheumatology, 31(6), 921-929. 
Myers, L. B. (2010). The importance of the repressive coping style: findings from 30 years of research. Anxiety, Stress \& Coping, 23(1), 3-17.

National Institute for Health and Clincal Excellence (NICE) (2009a). Low back pain: Costing report Implementing NICE Guidance. Retrieved 16 March, 2012, from http://www.nice.org.uk/nicemedia/pdf/CG88CostReport.pdf

National Institute for Health and Clincal Excellence (NICE) (2009b). Low back pain: early management of persistent non-specific low back pain. Retrieved 20 August, 2012, from http://guidance.nice.org.uk/CG88

Phipps, S., \& Steele, R. (2002). Repressive adaptive style in children with chronic illness. Psychosomatic Medicine, 64(1), 34-42.

Prasertsri, N., Holden, J., Keefe, F. J., \& Wilkie, D. J. (2011). Repressive coping style: Relationships with depression, pain, and pain coping strategies in lung cancer out patients. Lung Cancer, 71(2), 235-240.

Reynolds, W. M. (1982). Development of reliable and valid short forms of the marlowe? crowne social desirability scale. Journal of Clinical Psychology, 38(1), 119-125.

Roland, M., \& Fairbank, J. (2000). The Roland-Morris disability questionnaire and the Oswestry disability questionnaire. Spine, 25(24), 3115-3124.

Roland, M., \& Morris, R. (1983). A study of the natural history of back pain: part I: development of a reliable and sensitive measure of disability in low-back pain. Spine, $8(2), 141-144$.

Spielberger, C. D., Gorssuch, R. L., Lushene, P. R., Vagg, P. R., \& Jacobs, G. A. (1983). Manual for the State-Trait Anxiety Inventory. Mountain View: Consulting Psychologists Press.

Strahan, R., \& Gerbasi, K. C. (1972). Short, homogeneous versions of the Marlowe-Crowne Social Desirability Scale. Journal of Clinical Psychology, 28, 191-193.

Upadhyaya, A., \& Stanley, I. (1993). Hospital anxiety depression scale. The British Journal of General Practice, 43(373), 349.

Viggers, L. C., \& Caltabiano, M. L. (2012). Factors affecting the psychological functioning of Australian adults with chronic pain. Nursing \& Health Sciences, 14(4), 508-513.

Walsh, K., Cruddas, M., \& Coggon, D. (1992). Low back pain in eight areas of Britain. Journal of Epidemiology and Community Health, 46(3), 227-230.

Weinberger, D. A., Schwartz, G. E., \& Davidson, R. J. (1979). Low-anxious, high-anxious, and repressive coping styles: psychometric patterns and behavioral and physiological responses to stress. Journal of abnormal psychology, 88(4), 369.

Woby, S., Watson, P., Roach, N., \& Urmston, M. (2005). Coping strategy use: does it predict adjustment to chronic back pain after controlling for catastrophic thinking and selfefficacy for pain control? Journal of Rehabilitation Medicine, 37(2), 100-107.

Woby, S. R., Roach, N. K., Urmston, M., \& Watson, P. J. (2007). The relation between cognitive factors and levels of pain and disability in chronic low back pain patients presenting for physiotherapy. European Journal of Pain, 11(8), 869-877.

Woby, S. R., Roach, N. K., Urmston, M., \& Watson, P. J. (2008). Outcome Folowing a physiotherapist led intervention for chronic low back pain: the important role of cognitive processes. Physiotherapy, 94, 115-124.

Woby, S. R., Watson, P. J., Roach, N. K., \& Urmston, M. (2004). Adjustment to chronic low back pain - the relative influence of fear-avoidance beliefs, catastrophizing, and appraisals of control. Behaviour Research and Therapy, 42(7), 761-774.

Zigmond, A. S., \& Snaith, R. P. (1983). The hospital anxiety and depression scale. Acta Psychiatrica Scandinavica, 67(6), 361-370. 
Table 1. Summary of the mean $( \pm S D)$ demographic data for repressor, low-anxious, defensive high-anxious and high-anxious groups with back pain.

\begin{tabular}{|c|c|c|c|c|}
\hline & Repressor & Low-anxious & Defensive high-anxious & High-anxious \\
\hline Age (years) & $52( \pm 14.8)$ & $53( \pm 13.8)$ & $48( \pm 13.8)$ & $38( \pm 13.8)$ \\
\hline $\operatorname{Sex}(M / F)$ & $9 / 1$ & $13 / 2$ & $10 / 4$ & $11 / 7$ \\
\hline Trait Anxiety (STAI) & $25.1( \pm 3.5)$ & $26.4( \pm 2.9)$ & $52.7( \pm 10.5)$ & $47.5( \pm 5.6)$ \\
\hline Defensiveness (MC-SDS) & $8.6( \pm 0.6)$ & $5.0( \pm 0.4)$ & $8.5( \pm 0.2)$ & $4.7( \pm 1.5)$ \\
\hline Rating of worst pain & $4.4( \pm 1.7)$ & $4.7( \pm 1.9)$ & $6.1( \pm 3.3)$ & $6.6( \pm 2.1)$ \\
\hline Rating of present pain & $2.1( \pm 1.7)$ & $2.0( \pm 1.7)$ & $2.0( \pm 2.2)$ & $3.0( \pm 2.4)$ \\
\hline Disability (RDQ) & $1.0( \pm 1.8)$ & $3.0( \pm 2.0)$ & $7.0( \pm 5.0)$ & $6.0( \pm 6.0)$ \\
\hline Depression (HADS) & $1.5( \pm 1.7)$ & $2.6( \pm 2.5)$ & $7.3( \pm 4.7)$ & $5.0( \pm 3.6)$ \\
\hline $\begin{array}{l}\text { Rating of ability to work }(0 \\
=\text { no change, } 10=\text { extreme } \\
\text { change })\end{array}$ & $0.5( \pm 0.8)$ & $1.0( \pm 1.9)$ & $3.0( \pm 0.5)$ & $2.0(1.8)$ \\
\hline
\end{tabular}




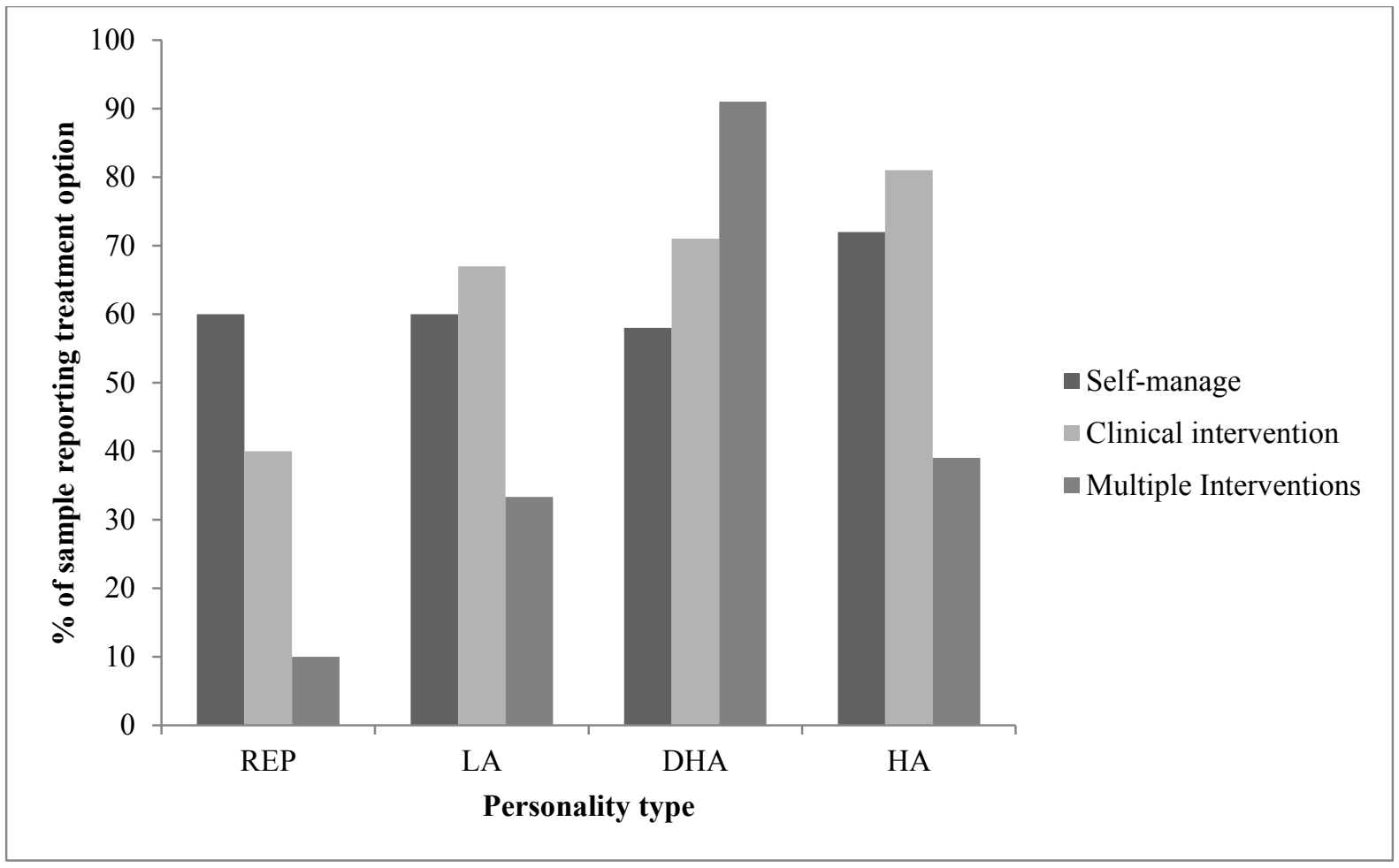

Figure 1. The percentage of treatment options used by repressors (REP), low-anxious (LA), defensive high-anxious (DHA) and high-anxious (HA) participants. 